\title{
Estimating the social costs of firearms: application to the Portuguese case ${ }^{1}$
}

\author{
Joana Matos Dias ${ }^{\mathrm{a},{ }^{\star}}$ and Pedro Godinho ${ }^{\mathrm{b}}$ \\ ${ }^{a}$ Faculdade de Economia and Inesc-Coimbra, Universidade de Coimbra \\ ${ }^{\mathrm{b}}$ Faculdade de Economia and GEMF, Universidade de Coimbra
}

Av. Dias da Silva, 165, 3004-512 Coimbra, Portugal

\begin{abstract}
In this paper we present a methodology for estimating social costs associated with firearm incidents, and present some results regarding the application of the methodology to Portugal. We consider social costs associated with such incidents, including medical care costs, losses in productivity and also intangible costs, like the valuation of the loss of quality of life, measured by safety per se values. We conclude that the intangible costs constitute the main slice of the total costs, in accordance with what has been reported by other authors for other countries, but the annual average cost per inhabitant is low when compared with other countries' realities.
\end{abstract}

Keywords: social costs, cost of crime, evaluation methods

\section{Introduction}

Portuguese people usually consider themselves to be gentle and non violent. However, official statistics show a significant upward trend in crime, and violent crime in particular (DGPJ, 2009). The number of firearms used in recorded crimes also suffered a significant increase, from 1247 firearms in 1994 to 6747 firearms in 2008 (DGPJ, 2009). There are also some signs of an abnormally large number of firearms in Portuguese households: in fact, there are 1.4 million licensed firearms, although it is possible that some of these firearms are no longer operational or have been destroyed (RTP, 2009). Most of the licensed firearms are for hunting purposes (800 000) and only 24000 for self-defence (Público, 2010). Adding to these numbers, it is believed that the number of illegal firearms in Portuguese households is approximately equal to the licensed ones (Jornal de Notícias, 2009). This leads to more than one weapon per four inhabitants, a figure that is sharply higher than the world-wide average of one weapon for every 10 people estimated by the Control Arms campaign (Control Arms, 2003, p. 19). Additionally, some high profile violent crimes have, in recent years, led to an increased

\footnotetext{
${ }^{1}$ We would like to thank an anonymous referee for his/her comments.

This work has been developed within the project "Violência e Armas ligeiras: um retrato português" (2007-2010), financed by the Portuguese Science Foundation (PTDC/SDE/72227/2006/FCOMP-01-0124-FEDER-007559).
}

Copyright @ $200 x$ Inderscience Enterprises Ltd. 


\section{Dias and Godinho}

awareness of the risk created by firearms in the Portuguese society, as well as to an increasing fear of violent crimes.

The Portuguese government has published legislation that aimed at reducing violent crime and the use of firearms. Before 2006, the legislation regulating the ownership and licensing of weapons was based on a law-decree from the year 1949, updated by several other bits of legislation that formed a complex and outdated legislative web, often hard to apply (MAI, 2010). In 2006, an integrated law regulating the ownership and carrying of weapons was approved by the Portuguese parliament. This law (Diário da República, 2006) makes it harder to get a license for owning and carrying a potentially lethal firearm. In general, such licenses may only be granted to people who show that they need it, either for professional reasons, special circumstances of self-defence or property defence, or for hunting. The possibility of getting such a license also depends on the individual's criminal record, physical and psychological fitness. Additionally, applicants to a license must attend a course about the technical and civic aspects of firearm possession and usage, and have to achieve a positive grade. The licenses are valid for a limited period of 5 or 10 years, according to the type of firearm, and at the end of this period the license holders must attend and pass an updating course in order to keep the license. Along with this law came an amnesty for holders of unlicensed firearms that would either acquire a license or hand them over to the police until 20 December 2006.

In 2008, a surge in violent crime caused public alarm in Portugal, leading the government to change the law (Público, 2008). The new law, published in 2009, imposes tougher sanctions for the illegal possession, carrying and use of weapons (Diário da República, 2009b).

In this article, we estimate the costs associated with firearms incidents in Portugal, in the period from 2003 to 2008. By choosing this period, we intend to determine whether the 2006 weapons law had a significant short-term impact on the costs of firearms incidents. We do not consider other costs like the costs associated with the anticipation of firearms crimes (costs incurred by the population to avoid being a crime victim - alarm systems, insurance, lifestyle changes), costs associated with the social response to firearms crimes (judicial system, criminal detention), nor more comprehensive costs usually referred to in the literature as fear of crime costs.

Data availability is a crucial feature in this kind of work, and defines the type of costs that can be incorporated into the analysis. The available data allowed us to include in this study medical care costs incurred to in public hospitals, costs associated with productivity losses and intangible costs associated with the victims (pain, suffering, loss of quality of life). We had to leave out other important social costs as property value losses or judicial costs.

It is also important to underline that the present study has the objective of estimating the costs, so we do not consider positive economic social effects that can also be associated with the existence of firearms. As a matter of fact, the existence of firearms boosts certain economic activities, like the selling of alarm and safety systems, tourism related to hunting activities, for instance, and can even be seen as avoiding some criminal activities. Lott (2000) reports a negative relation between the prevalence of arms and the number of homicides, although other authors (Cook and Ludwig, 2006, for instance) estimate a relation with opposite contours. The positive effects to society associated with firearms are out of the scope of this article.

This article is organized as follows: in the next section some of the existing literature is described; section 3 will thoroughly describe the available data; section 4 will describe 
the applied methodology; section 5 will present the main results and section 6 will present some conclusions.

\section{State-of-the-art}

Violence and crime have been, for a long time, a permanent concern of modern societies. The quantification of the costs associated with crime and violence phenomena has been the focus of study for several researchers. This quantification allows the assessment of the associated social impact as well as the policies that aim to fight against violence. Dhiri and Brand (1999) present a guide for the assessment of costs and benefits related to programs of criminality reduction, and the European project "Mainstreaming Methodology for Estimating Costs of Crime" (MMECC, 2008) intends to make a synthesis of the techniques for estimating the costs of criminality.

The costs associated to crime and violence can be classified among several categories. Walker $(1992,1997)$ makes a first distinction between financial and economic costs. Financial costs are the ones that correspond to illegal transfers of property or purchasing power. As there exists an offender that will benefit by an amount similar to the one that is taken from the victim, these costs will cancel each other when one considers the society as a whole. The economic costs are the ones incurred by society as a whole, and are associated with the loss of resources due to crime and violence, or to the assignment of resources to the avoidance or minimization of the consequences of these phenomena.

Brand and Price (2000) and MMECC (2008) split the crime costs in: costs in anticipation of crime, costs as a consequence of crime and costs in response to crime. The costs in anticipation of crime include costs relative to the protection against crime (safety, alarms, changes in lifestyles, etc.), the cost of fear and the cost of crime prevention programs. The costs as a consequence of crime include, among others, property losses, productivity losses, medical care costs, school absence, suffering and loss of quality of life, and costs of victim support services. The costs as a response to crime include costs incurred by the police and security forces, judicial and prison systems.

The inexistence of reliable data introduces important restrictions in studies about the costs of crime and violence. Brand and Price (2000) estimate the costs of crimes, for different crime categories, in England and Wales in 1999-2000, reaching a total approximate value of 60000 million pounds. For some of the categories considered, the authors chose to present higher and lower estimates. Walker $(1992,1997)$ and Mayhew (2003) estimate the costs of crime in Australia. For some costs categories, the authors state the impossibility of performing the estimation due to the lack of data, and present some values as being only lower bounds to the real incurred costs. Walker (1992) obtains a cost estimate of between 11000 and 21000 million dollars a year, indicating that if one takes into consideration the costs categories that could not be estimated, these costs might rise up to 27000 million dollars. Walker (1997) updates these costs, presenting values of between 11000 and 13000 million dollars; the author states that the inclusion of the costs categories that were not possible to quantify would increase these values up to at least 18000 million dollars. Mayhew (2003) obtains values near 32000 millions dollars, about 1600 dollars per person a year - approximately five per cent of the Australian Gross Domestic Product (GDP). 


\section{Dias and Godinho}

The costs associated with firearms incidents are particularly important, due to the political implications (for instance, in the definition of firearm ownership and licensing laws) and the risks associated with their existence. Most of the studies that discuss these matters come from the USA.

Max and Rice (1993) estimate that the costs associated with wounds caused by firearms in the USA amounted to 14400 million dollars in 1985 and 20400 million dollars in 1990. The authors consider the direct medical treatment costs, as well as rehabilitation, health insurance, productivity losses and even necessary home modifications to accommodate victims' disabilities. However, they do not consider intangible costs.

Miller and Cohen (1997) estimate a social cost of 126000 million dollars associated with firearms incidents in USA in 1992. Their analysis includes costs incurred by the emergency services, police investigation, medical care (including psychological treatment of the victims), administrative and intangible costs. Incidents with cutting and stabbing weapons are responsible for a number of deaths and wound survivors requiring medical treatment that is about 18 times higher than the same number related with firearms incidents. Despite that, the authors notice that the cut/stab incidents present a social cost significantly lower than the latter: about 46000 million dollars. Cook et al. (1999) estimate the medical care costs of the treatment of victims of firearms incidents. According to the authors, the total cost due to firearms incidents that took place in USA in 1994 was approximately 2300 million dollars.

Cook and Ludwig (2006) estimate the social costs associated with the existence of firearms in American homes. Using a regression model, the authors reach the conclusion that the existence of firearms in the civil society increases the homicide rate, estimating an elasticity of homicides with respect to gun prevalence between +0.1 and +0.3 . Based on these values, they estimate an annual marginal social cost of between $\$ 100$ and $\$ 1800$ for each household firearm.

Ludwig and Cook (2001) use survey data in a contingent valuation of the amount that the American society would be willing to pay to reduce firearms assaults by 30 per cent. The authors reach a value of 24500 million dollars. This amount corresponds to 1.2 million dollars for avoided injury and, considering some additional assumptions, it implies a statistical value of life of about 5.4 million dollars.

\section{Data}

Data availability has a significant impact on the type of results that may be obtained. With respect to data related to crime, it is often difficult to obtain information due to a number of reasons:

- The information is spread over several entities, that gather and treat the information independently;

- Many of the firearm incidents occur due to outlaw activities, and are not reported to any private or public entity;

- $\quad$ Firearm incidents and costs are strongly correlated with non quantifiable variables, like fear, feeling of insecurity, and so on. 
Nevertheless, even with data availability limitations, an analysis can be performed provided that precautionary principles are assumed both in the designing of the model and in the conclusions derived.

Considering the Portuguese case, the data that was available was the following:

- $\quad$ Number of deaths, by age classes, that were registered by the National Health System, in the period 2003 to 2008 . These deaths correspond to injured people that were submitted to medical treatments in public hospitals, and then died as a result of firearm inflicted injuries.

- Number of people that received medical treatment in a hospital, due to any kind of firearm inflicted injuries, total days of hospital internment and respective Diagnosis-Related Group (DRG), by age classes, registered by the National Health System between 2003 and 2008.

- $\quad$ Number of deaths due to firearm consummated murder or victims of aggravated assault, by age classes, registered by Polícia Judiciária ${ }^{\mathrm{i}}$ between 2003 and 2008.

- $\quad$ Data available from Instituto Nacional de Medicina Legal (National Forensics Institute), related to firearm inflicted injuries that were subjected to forensic investigation, between 2003 and 2008.

- Health Ministry's decree orders 132/2009, 30 January, and 839 A/2009, 31 July, that approve the price lists applied to the National Health Services regarding each DRG, and the corresponding regulations (Diário da República, 2009a and 2009c);

- $\quad$ Forecast of the Portuguese population, from 2009 to 2060, that corresponds to the central scenario of forecasts performed by Instituto Nacional de Estatística (INE National Institute of Statistics) (INE, 2009b);

- Values and forecasts for the Portuguese GDP, between 2003 and 2014, and values for the Portuguese Average Consumer Prices and inflation, between 2002 and 2009, given by the International Monetary Fund (IMF) (IMF, 2010).

Considering the number of deaths, it should be noted that there are three different data sources: National Health Service, that reports deaths that were a consequence of firearm inflicted injuries subjected to hospitalized treatment; Polícia Judiciária, where only firearm consummated homicides and aggravated assaults are considered; National Forensics Institute, where only the mortal victims subjected to forensic investigation are reported. It was not possible to conciliate the different numbers provided by the different sources. To avoid the possibility of double counting, we chose to consider only the number of victims reported by Polícia Judiciária, because these are the largest figures among the three sources and should thus be the closest to the true number of deaths. Data from Polícia Judiciária, however, does not allow us to separate between homicide and some aggravated assault victims. Considering that aggravated assault is defined by the Portuguese Penal Code (article $144^{\circ}$ ) as inflicting to the victim major permanent and irreversible damages, and considering also that Polícia Judiciária defines these occurrences as 'lethal incidents', we chose to equate these situations to death. 
Considering injured victims, we chose to use the numbers provided by the National Health System. As these numbers only account for the victims that received medical treatment in a hospital, it is likely that they are a lower bound to the real number of injured victims.

It was not possible to quantify costs associated with forensic investigation, due to the lack of data that could provide information on the type of procedures performed and their costs.

\section{Applied Methodology}

The costs that were estimated were medical care costs, productivity losses and intangible costs. In what follows, we will describe the methodology applied, resorting to the Portuguese case study.

In all calculations, we consider constant 2009 prices. This means that all values that correspond to years prior to 2009 are converted to 2009 euros by applying the appropriate inflation rates. Also, all estimations involving years after 2009 use constant 2009 prices (that is, they do not take inflation into account after this year). We also use a discount rate that considers constant prices - that is, the discount rate does not incorporate the effects of inflation.

\section{Medical care costs}

The available data allowed us to estimate the costs incurred by the National Health System in the treatment of firearms injuries. To that end, we considered all the records of injured people that received medical treatment in hospitals due to firearms incidents, in the period 2003 to 2008. For each injured patient, the assigned DRG was considered, as well as the total internment days. Considering the costs associated with each DRG, which are defined by decree orders 132/2009 and 839 A/2009 (Diário da República, 2009a and 2009c), and the defined imputation rules, it was possible to reach a cost for each patient. According to the imputation rules, we considered the distinction between a short and long episode, and between surgical and non-surgical episodes.

Whenever the injured patient was younger than 14 years old, we considered the existence of an accompanying adult during all the internment days, and the proper daily cost. The emergency episode was only considered in situations that correspond to zero days of internment. This means that the patient received medical treatment at the hospital but was discharged from the hospital in the same day. The cost associated with an emergency service depends on the emergency service classification where the victim received medical treatment (polyvalent emergency service, medical and surgical, or basic). This classification is defined by decree order 5414/2008 (Diário da República, 2008). As the information about the emergency service where the victims received medical treatment was missing, we chose to assign to each of these episodes the cost associated with the basic emergency service (the lowest of them all).

It was not possible to get any data on the type of attendance that was given to patients after being discharged from the hospital. This makes it impossible to estimate costs associated with after internment medical consultations, physical and psychological rehabilitation, medication costs, and so on. We can thus conclude that the estimated National Health System costs are being underestimated. 
Estimating the social costs of firearms: application to the Portuguese case

\section{Productivity losses}

The calculation of productivity losses should consider all the time that the victim would be working, but that is not due to causes that are related with firearms incidents. It should be noted that there is a productivity loss whether the victim loses her working income or not.

Considering the available data, there will be a productivity loss associated with every injured or mortal victim. If the victim is an injured child, under 14 years old, the productivity loss was nevertheless considered because we assume that there is a working active accompanying adult that will not work during all the internment days ${ }^{\mathrm{ii}}$.

The productivity loss of a gunshot survivor should consider not only the internment period, but also the total time that the person is prevented from working after being discharged from the hospital. The available data did not allow us to consider the productivity losses associated with recovery time away from hospital.

In order to be able to calculate productivity losses, it was necessary to estimate a daily per capita GDP value. We considered the values and forecasts of the IMF for 2003 to 2014 (IMF, 2010). For 2015 and beyond, we considered an average long term GDP growth rate of two per cent. It was considered that the working age population is composed of the individuals between 20 and 65 years old ${ }^{\mathrm{iii}}$. To obtain the numbers of those individuals, we used the INE central forecasts for Portuguese population, available for all years until 2060 (INE, 2009b). Beyond the year 2060, the population was considered constant. We were able to calculate a GDP value for working age person, for each year of analysis. Starting with the value of GDP per working age person, a daily value was estimated and considered as the daily average productivity loss. Noticing that the internment days can occur on both weekends and holidays, and considering that under the Portuguese Law the victims will be compensated with new rest days in the latter case but not in the former, we chose to consider a working year as being made of 335 days (that is, we included weekends and excluded holidays). All internment days are then regarded as days of the working year in which the injured person is unable to work - an internment day leads to a loss of about 0.3 per cent of the working year, and to the corresponding loss in annual per capita GDP.

\section{Fatalities}

In order to be able to calculate the productivity losses due to mortal victims, it is necessary to account for the age of the victims, so that the number of lost working years can be estimated. The available age classes are from 0 to 14 years old; five years intervals between 15 and 84 years old; more than 85 years old. The data also reports a residual number of victims whose age is not known. For these victims, the productivity loss was calculated as the average productivity loss considering the total number of victims in each year of the analysis. We considered that all victims aged less than 66 years old were working people, so we proceeded to calculate the productivity loss associated with each death. For each of the mortal victims that occurred in each year from 2003 to 2008, the estimated value of the productivity loss in each lost working year was calculated. That estimate was defined as the average annual GDP value per working age person. As an example, a victim that was 17 years old at the time of his death in the year 2003 was considered to be working from the year 2006 to 2051. For each one of these years, the productivity loss was considered equal to the annual GDP value per working age person. 


\section{Dias and Godinho}

To estimate the total impact in productivity of a single death, we should discount to the year of death the productivity losses of all future years. To perform such calculation, we need to decide on a discount rate. Several different authors have chosen different discount rates to calculate productivity net present values. Max and Rice (1993) use a discount rate of six per cent, and Corso et al. (2007) use a discount rate of three per cent. Miller and Cohen (1997) use a discount rate of two and one-half per cent, based on the range of values used by courts when defining the monetary compensations due to injury losses. Dhiri and Brand (1999) consider a discount rate of six per cent, equal to the discount rate used by the Central Bank of England.

The discount rate to use should reflect a social preference rate. In a way similar to what is done by Dhiri and Brand (1999), in this study we tried to find a return rate that was officially defined and that would express that social preference. We considered that the best approximation would be four per cent, a discount rate defined in decree order 13 208/2003 as the discount rate to use in economic-financial studies for the launching of private-public partnerships (Diário da República, 2003). Therefore, the Net Present Value of productivity losses was calculated using a discount rate of four per cent.

\section{Severe and Slight Injuries}

The productivity losses associated with injured patients should consider the hospital internment days, as well as all the days after discharge from the hospital such that the patient is still unable to work. It should also consider possible reversible or irreversible consequences of the incident that could have an effect on the patient's ability to perform the usual working tasks (namely physical or psychological disabilities). Based on the available data, we could only consider productivity losses associated with hospital internment days (it was not possible to gather information about the patients follow-up after discharge). Therefore, the estimated costs are a lower bound on the true social costs incurred.

In the estimation, we only considered productivity losses associated with patients belonging to working age population (between 20 and 65 years old). When children are involved (from zero to 14 years old), we assumed that an accompanying adult was present during all the internment days, and considered the corresponding productivity losses.

Some authors consider it appropriate to include the productivity losses associated with children in school age due to missing school days (Cohen 2005, for instance). Nevertheless, besides the fact that we did not have available data that would allow this quantification, it is also difficult to estimate the value associated with a missed school day. This is why we did not consider that term in the calculation of productivity losses.

\section{Intangible costs}

The intangible costs related to pain, suffering and lost quality of life are the most difficult costs to be quantified. Nevertheless, they usually constitute the most important slice of total costs.

An individual, no matter the level of productivity, will be willing to pay so that the probability of premature death or the probability of getting injured in a firearm incident is diminished. Similarly, an individual will also be willing to pay in order to decrease the probability of other individuals dying prematurely or getting injured, due to familiar and friendship connections, altruistic feelings, or other benefits arising from the reduction of 
firearm injury risk to the population in general (Ludwig and Cook, 2001). This willingness to pay shows a preference for reducing the risks associated with this kind of incidents, and can be quantified through a value that is usually known as the value of safety per se. This value can be empirically measured as the value of a statistical life (Bickel et al., 2006). It is important to note that this value does not intend to measure the monetary value of a life, but instead the value that corresponds to a slight change in the perceived risk of an individual being hurt or killed in consequence of a firearm incident.

The values of a statistical life that are used in published studies about crime or firearm incident costs present significant differences. There are no estimates specifically related to crime risks, so estimates originating from other contexts are often used (Cohen, 1990). As already said in section two, Ludwig and Cook (2001) estimate the value of a statistical life in 5.4 million dollars (1998 prices), based on survey data related to the willingness to pay to reduce firearm assaults. Miller and Cohen (1997) use the value of 2.5 million dollars (1993 prices), based on studies related to the acquisition of smoke detectors, safety belt usage and speed reduction during storms. Viscusi (1998) considers values between three and seven million dollars, based on studies regarding the risk of work accidents. Mayhew (2003) uses substantially lower values, of about 400 thousand dollars per life (2001 prices), based on the values used by Bureau of Transport Economics to assess the car crash accident costs.

In some countries the safety per se values are defined for fatalities and slight and severe injuries, in the quantification of road accident costs. Several authors advocate the use of these values in the estimation of social costs associated with violence and crime (Brand and Price, 2000; Mayhew, 2003; for instance). In the present study, we also chose to use these values of safety per se. Specifically, we used the values that are recommended for Portugal by the European project "HEATCO - Developing Harmonised European Approaches for Transport Costing and Project Assessment" (Bickel et al., 2006). This project recommends different safety per se values for the different countries in the European Union. The values that should be applied to Portugal are depicted in Table 1.

Table 1 Safety per se Values Recommended by the HEATCO Project to Portugal in $€ 2002$ (source: Bickel et al. 2006)

\begin{tabular}{|l|l|l|}
\hline Fatality & Severe injury & Slight injury \\
\hline $730000 €$ & $95000 €$ & $7300 €$ \\
\hline
\end{tabular}

The values in Table 1 were updated to $€ 2009$, considering the average consumer price index between 2002 and 2009. An inter-temporal elasticity to GDP per capita growth of 1.0 was considered, as recommended by the HEATCO project (Bickel et al., 2006). This elasticity and GDP changes were applied to the values presented in Table 1 in order to obtain the values of safety per se for the years 2003 to 2008 (presented in Table 2). 
Dias and Godinho

Table 2 Safety per se Values for Years 2003 to 2008, in € 2009

\begin{tabular}{|l|l|l|l|}
\hline Year & Fatality & Severe injury & Slight injury \\
\hline 2003 & $843867 €$ & $109818 €$ & $8439 €$ \\
\hline 2004 & $851157 €$ & $110767 €$ & $8512 €$ \\
\hline 2005 & $854451 €$ & $111196 €$ & $8545 €$ \\
\hline 2006 & $862834 €$ & $112287 €$ & $8628 €$ \\
\hline 2007 & $877093 €$ & $114142 €$ & $8771 €$ \\
\hline 2008 & $874389 €$ & $113790 €$ & $8744 €$ \\
\hline
\end{tabular}

The safety per se values make a distinction between severe and slight injuries, whilst the values related with firearm injuries do not consider such distinction. Therefore, we followed the recommendations of Autoridade Nacional de Segurança Rodoviária ${ }^{\text {iv }}$ (ANSR) and the definition used in counting injured people in road accidents. According to ANSR, a severely injured person is a victim whose injuries require a hospital internment of more than 24 hours. A slightly injured person is a victim that is not a severely injured one (ANSR, 2009). This definition was applied, considering the total number of internment days of each firearm incident victim.

\section{Results}

Table 3 presents the total number of firearm incident victims, categorized in mortal, severely injured and slightly injured victims, for the years 2003 to 2008 .

Table 3 Number of Firearm Incident Victims: victims of lethal accidents reported by Polícia Judiciária; severely and slightly injured victims reported by the National Health Service, as victims that received medical treatment in a hospital

\begin{tabular}{|l|l|l|l|}
\hline Year & Fatalities* & Severe injuries & Slight injuries \\
\hline 2003 & 166 & 335 & 60 \\
\hline 2004 & 150 & 274 & 76 \\
\hline 2005 & 126 & 262 & 52 \\
\hline 2006 & 200 & 281 & 33 \\
\hline 2007 & 106 & 236 & 39 \\
\hline 2008 & 132 & 231 & 26 \\
\hline
\end{tabular}

*: All victims of lethal incidents, as defined by Polícia Judiciária (includes some victims of aggravated assaults).

The intangible costs (pain, suffering, and lost quality of life), productivity losses and medical care costs are presented in Table 4. For the years 2003 to 2008, the average annual cost totalled approximately 108 million euros ( $€ 2009)$. 
As can be seen from the table, the largest slice of total costs (about 63 per cent) concerns safety per se, including intangible factors like pain, suffering and lost quality of life. The productivity losses account for about 36 per cent of total costs, and medical care costs represent less than one per cent ( 0.7 per cent). It may seem that safety per se costs have an excessive weight, and medical care costs present a value too low. Nevertheless, if we look at the equivalent costs estimated by Miller and Cohen (1997), we can see that safety per se accounts for about 68 per cent, and productivity losses represents nearly 30 per cent of total costs, the medical care costs being only two per cent of total costs. Therefore, the costs distribution obtained in the present study is quite similar to the one presented by Miller and Cohen.

The average costs per inhabitant and victim were also estimated. To estimate the costs per inhabitant we used an approximate value of the total number of inhabitants equal to INE estimate for the resident Portuguese population on 31 December 2008: 10627250 inhabitants (INE, 2009a). The calculated values are presented in Table 5.

Values in Table 5 do not allow the identification of a clear trend in the average cost per inhabitant or per victim. This lack of trend may be justified by the lack of a clear tendency in the evolution of the number of mortal victims along the years, mortal victims being the ones that have the largest impact in the total cost (as can be verified by looking at Table 3). There seems to be a downward trend, interrupted by the atypical year of 2006 where the number of mortal victims and severely injured victims increases. So, there seems to have been some reduction on the costs associated with firearm incidents after the 2006 weapons law was applied. However, this reduction cannot be considered very significant, and it may simply be due the continuance of a previous trend.

Table 4 Intangible Costs (pain, suffering and lost quality of life), Productivity Losses and Medical Care Costs Associated with Firearm Incidents $\left(10^{3} € 2009\right)$

\begin{tabular}{|l|l|l|l|l|l|}
\hline Year & Safety per se & $\begin{array}{l}\text { Lost productivity: } \\
\text { fatalities* }\end{array}$ & $\begin{array}{l}\text { Lost productivity: } \\
\text { injured victims }\end{array}$ & $\begin{array}{l}\text { Medical care } \\
\text { costs }\end{array}$ & $\begin{array}{l}\text { Total per } \\
\text { year }\end{array}$ \\
\hline 2003 & 147766 & 90929 & 243 & 1392 & 240330 \\
\hline 2004 & 136820 & 81064 & 194 & 1507 & 219586 \\
\hline 2005 & 114341 & 62946 & 235 & 1278 & 178800 \\
\hline 2006 & 176626 & 103084 & 286 & 1627 & 281622 \\
\hline 2007 & 98278 & 52434 & 187 & 1303 & 152203 \\
\hline 2008 & 119139 & 65070 & 247 & 1425 & 185880 \\
\hline $\begin{array}{l}\text { Annual } \\
\text { average }\end{array}$ & 132162 & 75921 & 232 & 1422 & 209737 \\
\hline
\end{tabular}

*: All victims of lethal incidents, as defined by Polícia Judiciária (includes some victims of aggravated assaults). 
Dias and Godinho

Table 5 Total average costs per inhabitant and victim (including safety per se, lost productivity and medical care costs) (€ 2009)

\begin{tabular}{|l|l|l|}
\hline Year & Average cost per inhabitant & Average cost per victim \\
\hline 2003 & $22.61 €$ & $428 \times 10^{3} €$ \\
\hline 2004 & $20.66 €$ & $439 \times 10^{3} €$ \\
\hline 2005 & $16.82 €$ & $406 \times 10^{3} €$ \\
\hline 2006 & $26.50 €$ & $548 \times 10^{3} €$ \\
\hline 2007 & $14.32 €$ & $399 \times 10^{3} €$ \\
\hline 2008 & $17.49 €$ & $478 \times 10^{3} €$ \\
\hline Annual average & $19.74 €$ & $450 \times 10^{3} €$ \\
\hline
\end{tabular}

We also notice, in Table 5, that the average annual cost per inhabitant is quite low, especially if we take into consideration the average values per inhabitant in similar studies that refer to the USA. The differences can be explained in part due to the differences between the two countries, namely differences in productivity and wealth, but also due to the number of existing firearms (in USA, approximately 90 guns for 100 inhabitants in 2007 (Reuters, 2007)), and in the percentage of the population that is a victim of firearm incidents (the number of firearm homicides per 100000 inhabitants is more than six times higher in the USA than in Portugal (Committee on Law and Justice, 2004)). Differences may also be explained by the different data availability: whilst the USA studies consider the total number of firearm incident victims, the present study only considers the mortal victims reported by Polícia Judiciária and the injured victims that received medical treatment in hospitals. Thus it is possible that the present study is omitting some victims that are not registered in the health system or in the judicial system. That is also the reason why we did not consider appropriate to perform a detailed comparison between the results presented here and the results presented in other studies concerning different countries.

We felt, however, appropriate to compare the reality of firearms with that of cut/stab incidents. Table 6 shows a comparison between the data and estimated costs considering these two realities.

As expected, despite the fact that cut/stab incidents are responsible for more victims in general (about 15 per cent more), the number of mortal victims is about 2.8 times greater in firearms' incidents. The total estimated costs are 42.7 per cent lower than the costs associated with firearms. The relation between values obtained is in line with the results reported by Miller and Cohen (1997) for the USA. 
Estimating the social costs of firearms: application to the Portuguese case

Table 6 Comparison of the Number of Victims and Associated Estimated Costs between Firearm and Cut/Stab Incidents (average annual values)

\begin{tabular}{|l|l|l|}
\cline { 2 - 3 } \multicolumn{1}{c|}{} & Firearms & Cut/stab \\
\hline Number of mortal victims* & 147 & 53 \\
\hline Number of severely injured victims & 270 & 370 \\
\hline Number of slightly injured victims & 48 & 110 \\
\hline Safety per se $\left(10^{3} €\right)$ & 132162 & 60636 \\
\hline Productivity losses: mortal victims $\left(10^{3} €\right)^{*}$ & 75921 & 27198 \\
\hline Productivity losses: injured victims $\left(10^{3} €\right)$ & 232 & 184 \\
\hline Medical care costs $\left(10^{3} €\right)$ & 1422 & 1442 \\
\hline Total costs $\left(10^{3} €\right)$ & 209737 & 89461 \\
\hline
\end{tabular}

*: All victims of lethal incidents, as defined by Polícia Judiciária (includes some victims of aggravated assaults).

\section{Conclusions}

In this article we have described a methodology for estimating social costs that are incurred as consequence of firearm incidents, and applied it to the Portuguese case. Taking the available data into consideration, we chose to estimate the medical care costs, productivity losses and intangible costs (pain, suffering and lost quality of life) associated with mortal, slightly injured and severely injured victims. The data limitations and the principle of precaution of avoiding double counting forced us to consider as mortal victims those reported by Polícia Judiciária as victims of lethal incidents, which correspond to consummated firearm homicide mortal victims and some victims of aggravated assault. The total number of injured victims considered the victims that received medical treatment in hospitals as a consequence of a firearm incident, as reported by the National Health System. The lack of more reliable and complete data forces us to consider the presented results as a lower bound on the real social costs.

The social costs were estimated for the years of 2003 to 2008, and an average annual cost of approximately 210 million dollars (€2009) was obtained. This value leads to an average cost per inhabitant that is much lower than the values published in other studies, regarding other countries. It is possible that the differences are due to the differences between the countries, but they may also be related to the characteristics of the available data.

A weapons law, approved in 2006 by the Portuguese parliament, made it harder to get a license for owning and carrying a firearm, and in the same year there was also an amnesty for people who would either get a license or hand over unlicensed firearms to the police. These initiatives aimed at reducing firearms incidents. There seems to have been some reduction on the costs associated with firearm incidents after 2006, but we cannot be sure whether the new weapons law had some role in it, or whether it simply results from the continuance of a previous trend. As a future work, it will be interesting to check whether or not the changes made in 2009 in the weapons law, defining tougher 


\section{Dias and Godinho}

sanctions for the illegal possession, carrying and use of firearms, had a larger impact in the social costs of firearms-related incidents.

The comparison carried out with the cut/stab incidents allowed us to conclude that there were a greater number of cut/stab incidents, but a lower total cost associated. These smaller costs are explained by a smaller number of deaths. Such result may have some implications for policy-makers aiming at minimizing the costs of weapon-related incidents. In the first place, it seems to be legitimate to conclude that the focus should be put on firearms. In the second place, it seems that it might make sense to make it easier to acquire and possess non-lethal defensive weapons, like pepper spray or electrical defense weapons. In Portugal, buying or possessing such weapons requires a special license. Applicants to such a license must fill several conditions, including a proof that they need to possess such a weapon - so, it is not easy to obtain such a license. In spite of Portugal having a relatively low criminality rate, high profile criminal incidents, or localized surges in violent crime, are always bound to cause some alarm in the population. The difficulty in acquiring non-lethal defensive weapons, coupled with the existence of a large number of illegal firearms and hunting firearms in the society, may lead some alarmed citizens to follow the "easier" path of acquiring, or keeping, an illegal firearm for self-defence purposes. There may be accidents with such firearms, and they may even be stolen for being used in crimes. In order to reduce the total costs of weapon-related incidents, policy-makers might want to make it easier to acquire and possess non-lethal, defensive weapons, which, even in case of accidents, should have a much smaller social cost.

Throughout this paper, we tried to detail the methodology used, and that allowed us to reach the shown estimates, even in the absence of some data. It is important to notice that if governments want to make informed decisions about the use and possession of guns, a greater effort should be put in the collection and processing of detailed data that can be used as a basis for more accurate and complete estimates. As future research, it would be interesting to gather and treat data that would allow us to quantify the benefits associated with the possession of firearms. This is controversial subject, but that should also be taken into account when taking decisions regarding these matters.

\section{References}

ANSR. (2009) 'Principais Indicadores de Sinistralidade do Continente', Observatório de Segurança Rodoviária, Autoridade Nacional de Segurança Rodoviária, March 2009. Obtained through the Internet: $h t t p: / / w w w . a n s r . p t$ [accessed 1/8/2009].

Bickel, P., Friedrich, R., Burgess, A., Fagiani, P. et al. (2006) 'HEATCO Developing Harmonised European Approaches for Transport Costing and Project Assessment, Deliverable 5: Proposal for Harmonised Guidelines'. Obtained through the Internet: http://heatco.ier.uni stuttgart.de/HEATCO_D5.pdf [accessed 31/7/2009].

Brand, S. \& Price, R. (2000) 'The Economic and Social Costs of Crime', Home Office Research Study 217, London, Home Office.

Cohen, M.A. (1990) 'A note on the cost of crime to victims', Urban Studies, vol. 27,pp. 139146.

Cohen, M.A. (2005) The Costs of Crime and Justice, New York, Routledge.

Committee on Law and Justice. (2004) 'Firearms and Violence: A Critical Review', National Academy of Science. Obtained through the Internet: http://www.nap.edu/books/0309091241/html/53.html [accessed 23/3/2010]. 


\section{Estimating the social costs of firearms: application to the Portuguese case}

Control Arms. (2003) 'Shattered Lives: The Case for Tough International Arms Control', Amnesty International and Oxfam International. Obtained through the Internet: http://www.controlarms.org [accessed 21/3/2010].

Cook, P.J. \& Ludwig, J. (2006) 'The Social Costs of Gun Ownership', Journal of Public Economics, vol. 90, pp. 379-391.

Cook, P.J., Lawrence, B.A., Ludwig, J. \& Miller, T.R. (1999) 'The Medical Costs of Gunshot Injuries in the United States', Journal of the American Medical Association, vol. 282, pp. 447-454.

Corso, P.S, Mercy, J.A., Simon, T.R., Finkelstein, E.A. \& Miller, T.R. (2007) 'Medical Costs and Productivity Losses Due to Interpersonal and Self-Directed Violence the United States', American Journal of Preventive Medicine, vol. 32, pp. 474-482.

DGPJ. (2009) 'Estatísticas Oficiais da Justiça', Direç̧ão Geral da Política de Justiça. Obtained through the Internet: http://www.siej.dgpj.mj.pt [accessed 21/3/2010].

Dhiri, S. \& Brand, S. (1999) 'Analysis of Costs and Benefits: Guidance for Evaluators, Crime Reduction Programme', London, Home Office.

Diário da República. (2003) 'Diário da República - 2a Série', vol. 154, 7 July, 10136.

Diário da República. (2006) 'Diário da República - 1ª́rie A', vol 39, 23 February, 14621489.

Diário da República. (2008) 'Diário da República - 2ª Série', vol. 42, 28 February, 80838085.

Diário da República. (2009a) 'Diário da República - 1ª́rie' , vol. 21, 30 January, 660758.

Diário da República. (2009b) 'Diário da República - 1ª Série', vol. 147, 6 May, 25592604.

Diário da República. (2009c) 'Diário da República - 1ª́rie', vol. 147, 31 July, 4978(2) 4978(124).

IMF. (2010) 'World Economic Outlook Database', International Monetary Fund, April 2010. Obtained through the Internet: http://www.imf.org [accessed 14/7/2010].

INE. (2009a) 'Estimativas Provisórias de População Residente - Portugal, NUTS II, NUTS III e Municípios - 2008', Instituto Nacional de Estatística. Obtained through the Internet: http://www.ine.pt [accessed 1/8/2009].

INE. (2009b) 'Projecções de População Residente - Portugal - 2008 - 2060', Instituto Nacional de Estatística. Obtained through the Internet: http://www.ine.pt [accessed 1/8/2009].

Jornal de Notícias (2009) 'Contabilidade das Armas Ilegais em Portugal Aponta para os 1.4 Milhões', 14 January. Obtained through the Internet: http://jn.sapo.pt [accessed 21/3/2010].

Lott, J.R. (2000) More Guns, Less Crime: Understanding Crime and Gun-Control Laws, 2nd edition, University of Chicago Press, Chicago.

Ludwig, J. \& Cook, P.J. (2001) 'The Benefits of Reducing Gun Violence: Evidence from a Contingent-Valuation Survey Data', The Journal of Risk and Uncertainty, vol. 22, pp. 207-226.

MAI. (2010) 'Enquadramento Histórico', Ministério da Administração Interna - Controlo de Armas e Explosivos. Obtained through the Internet: http://armas.mai gov.info [accessed 21/3/2010].

Mayhew, P. (2003) 'Counting the Costs of Crime in Australia', Australian Institute of Criminology, Trends and Issues in Crime and Criminal Justice Series, $\mathrm{n}^{\circ} 247$.

Max, W. \& Rice, D.P. (1993) 'Shooting in the Dark: Estimating the Cost of Firearm Injuries', Health Affairs, vol. 12, pp. 171-185.

Miller, T.R. \& Cohen, M.A. (1997) 'Costs of Gunshot and Cut/Stab Wounds in the United States, with some Canadian Comparisons', Accident Analysis \& Prevention, vol. 29, pp. 329-341.

MMECC. (2008) 'Mainstreaming Methodology for Estimating Costs of Crime'. Obtained through the Internet: http://www.costsofcrime.org [accessed 31/7/2009].

Público (2008) 'Governo quer Prisão Preventiva para Todos os Crimes com uso de Arma', 29 August. Obtained through the Internet: http://www.publico.pt [accessed 21/3/2010]. 
Público (2010) 'Dez retratos do mercado das armas em Portugal', 7 February. Obtained through the Internet: http://jornal.publico.pt [accessed 23/3/2010].

Reuters (2007) 'U.S. most armed country with 90 guns per 100 people' 28 August. Obtained through the Internet: http://www.reuters.com [accessed 23/3/2010].

RTP (2009) 'PSP contabiliza 32 mil armas roubadas ou extraviadas em duas décadas', 28 July. Obtained through the Internet: http://tv1.rtp.pt [accessed 23/3/2010].

Viscusi, W.K. (1998) Rational Risk Policy: The 1996 Arne Ryde Memorial Lectures, Oxford University Press, New York.

Walker, J. (1992) 'Estimates of the Cost of Crime in Australia', Australian Institute of Criminology, Trends and Issues in Crime and Criminal Justice Series, $\mathrm{n}^{\circ} 39$.

Walker, J. (1997) 'Estimates of the Cost of Crime in Australia in 1996', Australian Institute of Criminology, Trends and Issues in Crime and Criminal Justice Series, $\mathrm{n}^{\circ} 72$.

${ }^{\mathrm{i}}$ Polícia Judiciária is the main police branch of criminal investigation in Portugal dedicated to fighting criminality.

${ }^{\text {ii }}$ In most Portuguese hospitals, 14 years old is the age limit for a child to be accompanied by an adult.

iii The choice of the 20 and 65 ages has to do with the fact that in Portugal there is a minimum of 12 years of compulsory education, and most people are allowed to retire at the age of 65 .

${ }^{\text {iv }}$ Autoridade Nacional de Sefurança Rodoviária (National Authority for Road Safety) is a Portuguese public institution responsible for the prevention of road accidents and for the definition and enforcement of road safety measures. 